\title{
Leveraging Technology to Promote Workplace Mental Health
}

\author{
Kristina Smith, Chanel Brown, and Benjamin Leikin \\ Ottawa Public Health
}

\begin{abstract}
The workplace has a significant impact on individuals' mental health and provides an ideal opportunity to address and enhance mental health. Ottawa Public Health created a series of videos and activities to support workplaces to take action on mental health. They have received national acclaim and are widely in use.
\end{abstract}

Keywords: mental health, workplace, mental health promotion, National Standard for Psychological Health and Safety in the Workplace, technology, videos

\section{RÉSUMÉ}

Le milieu de travail a une incidence importante sur la santé mentale des travailleurs. De ce fait, il constitue un espace privilégié où l'on peut s'attarder à la question de la santé mentale en vue de l'améliorer. Santé publique Ottawa a créé une série de vidéos et d'activités pour faciliter la mise en œuvre de mesures favorisant la santé mentale en milieu de travail. Saluées dans l'ensemble du pays, ces initiatives sont largement utilisées aujourd'hui.

Mots clés : santé mentale, milieu de travail, promotion de la santé mentale, Norme nationale sur la santé et la sécurité psychologiques en milieu de travail, technologie, vidéos

Kristina Smith, public health nurse on the Mental Health team, Ottawa Public Health, Ottawa, Ontario; Chanel Brown, public health nurse on the Mental Health team, Ottawa Public Health, Ottawa, Ontario; Benjamin Leikin, supervisor of the Mental Health team, Ottawa Public Health, Ottawa, Ontario.

This practice innovation was made possible through funding and content expertise from the Mental Health Commission of Canada; content development by Jason Haug, supervisor of the Public Health Information and Communication team, Ottawa Public Health; and adapted content from Mindful Employer Canada.

Correspondence concerning this article should be addressed to Kristina Smith, RN, BScN, Ottawa Public Health, 100 Constellation Drive, Ottawa, ON, K2G 6J8. Email: Kristina.smith@ottawa.ca 
Mental health is an issue of increasing importance within public health and workplaces across Canada, and for good reason. Over 500,000 Canadians miss work each week due to mental health problems and illnesses (Mental Health Commission of Canada, 2016). As well, the cost of a disability leave for a mental illness is almost double the cost of a leave due to a physical illness (Dewa, Chau, \& Dermer, 2010). With this need and growing awareness, the Mental Health Commission of Canada (MHCC) commissioned the National Standard for Psychological Health and Safety in the Workplace (the Standard). The Standard is the first of its kind in the world; it provides evidence-based tools and is a framework for addressing workplace mental health. It aims to put the importance of mental health and safety at the same level as physical health and safety. The Standard comprises 13 workplace psychosocial factors ("factors") affecting psychological health and safety.

Ottawa Public Health $(\mathrm{OPH})$ has been supporting workplaces to implement the Standard since its release in 2013. While working closely with workplaces, they frequently stated that the Standard was overwhelming, confusing, and challenging to implement. To better support workplaces, increase their awareness and knowledge on the Standard and help them take action on it, we partnered with the MHCC to bring the Standard to life. We did this by creating whiteboard animation videos for each of the factors and an accompanying Facilitator's Guide.

Through evaluations, feedback, and new partnership agreements we have learned that the video series has increased workplace employees' understanding and made the content of the Standard more accessible. In turn, this has helped workplaces take action and make mental health a priority.

\section{PARTNERSHIPS AND DEVELOPMENT}

Through our partnership with MHCC, we were fortunate to work with experts from Mindful Employer Canada on the development and review of the content for the videos and activities. In addition, MHCC and internal experts reviewed and provided meaningful feedback throughout the video development process. Internal OPH experts adapted the videos to French rather than using a direct translation. This approach was vital as it ensured that the videos designed for the francophone population had the same meaning and impact as the anglophone videos.

In order to ensure the videos met the needs of our target population, OPH collaborated with Workplace Safety and Prevention Services (WSPS) to conduct pilot testing with several focus groups. Representatives from more than 15 industries took part in the pilot testing and responded to questions based on a health equity approach, ensuring that there were no stigmatizing language or visuals, and that the videos had meaning for as many groups as possible. The pilot testing provided OPH with valuable feedback and suggestions for edits, which highlighted the need for a Facilitator's Guide to accompany the video series. The Facilitator's Guide provides a definition of each of the factors as well as questions for each video to help guide the conversation and help workplaces take action.

The workplace videos and Facilitator's Guide were incorporated into an existing National Mental Health campaign titled "have THAT talk" that allowed for greater access, reach, and the development of partnerships for the content. The workplace mental health videos received its own section within the campaign to highlight the importance and unique aspects of workplace mental health. 


\section{REACH AND INFLUENCE}

With the support of several major partners, including the MHCC and a Bell Canada campaign titled "Bell Let's Talk," the workplace "have THAT talk" video series and Facilitator's Guide were launched during Canada's Healthy Workplace month in October 2016.

The launch of the videos received major uptake across the country with partners like the Canadian Mental Health Association (CMHA), WSPS, and Bell promoting the videos on their social media platforms and websites.

Since the launch, the uptake and reach of the resources continues to this day. Local, provincial, and national organizations have entered into partnership agreements with OPH to use the videos and guide, and many more promote the videos through their channels. Some examples of video promotion include the following:

- The Canadian School of Public Service uses the videos on their website and promotes the videos to more than 220,000 federal government staff.

- Several sectors in the Government of Canada use the videos to develop internal policies and guidelines.

- WSPS use the videos in a Ministry of Labour training program to support organizations across Ontario with their journey towards implementation of the Standard.

- CMHA National have embedded the videos on their website.

- MHCC uses the videos for training employees called Being a Mindful Employee. This training was developed in partnership with the Canadian Centre for Occupational Health and Safety.

- The videos were highlighted in a Globe and Mail article titled A step by step plan to improve workplace mental health.

- Dr. Joti Samra, developer of Guarding Minds at Work and member of the University of Fredericton Psychological Health and Safety Certificates program, requested permission to incorporate the videos into her training and presentations.

- Mary Ann Baynton, the co-chair of the technical committee for the National Standard and Program Director for the Great-West Life Centre for Mental Health in the Workplace and developer of Mindful Employer Canada uses the videos in the online training, On the Agenda.

- Numerous public health units across Canada use the videos with workplaces in their communities.

- Colleges and universities use the videos for training with students and graduates.

\section{EVALUATION AND IMPACT}

OPH undertook an evaluation to gain a better understanding of the impact of a project of this magnitude. One aspect of the evaluation included OPH sending a follow up survey to clients regarding the effectiveness of the video series. The results received were positive and indicated that the videos are helping to make complex material in the Standard more understandable and supportive of workplaces intending to take action. 
Some of the results are as follows:

- $95 \%$ of respondents were satisfied with the quality of the videos

- $90 \%$ of respondents stated that the videos met their needs

- $90 \%$ stated that the videos increased awareness of the Standard and workplace mental health

- $53 \%$ of respondents at a four month follow-up stated that they had changed their practices at work as a result of the videos

\section{IMPLICATIONS}

To date, the have THAT talk video series have been viewed more than 1.6 million times worldwide. $\mathrm{OPH}$ continues to receive positive feedback from clients and partners about the effectiveness of the videos and guide. Workplaces have shared repeatedly that this resource has contributed to improved mental health practices and policies in their workplace. Partners continue to integrate this resource into online training and $\mathrm{OPH}$ continues to receive requests from clients to use the videos and guide on their internal websites.

Having a positive work culture where the workplace actively promotes mental health and works to prevent psychological harm is ethically and economically the correct thing to do. By leveraging technology and an innovative design, OPH made these videos easily accessible to the public. The videos highlight the importance of mental health in workplaces and allow all workplaces, big and small, to have THAT talk and take action on mental health.

\section{FUTURE DIRECTIONS}

To address mental health in the workplace, an integrated approach is required; one which includes protecting mental health, promoting mental health, and addressing mental health problems (Lamontagne, Martin, \& Page, 2014). Evidence shows that implementation of the National Standard for Psychological Health and Safety in the Workplace works best when employees are involved in the process and interventions are tailored to the needs of the workplace (Cancelliere et al., 2011). When businesses adopt policies and programs to address psychological health and safety, they incur between $15 \%$ to $33 \%$ fewer costs related to psychological health issues (Guarding Minds at Work, 2018).

Using the video series in any workplace is key to raising awareness and enhancing the discussion about mental health. Most importantly, the video series and accompanying guide is a valuable tool to allow workplaces to take action on the mental health of their most valuable asset, their staff. The discussion generated by the videos and guide will provide suggestions, opinions, and ideas from workers across all levels. The overall feedback received on the videos highlights an innovative and modern approach to the 13 factors that help support the development of mental health programming within the workplace.

With increased awareness and evidence, employers understand that adequately addressing mental health in the workplace will lead to a more productive and engaged workforce. Employers may be motivated to address mental health for a number of reasons, including economics, productivity, and compassion for the 
employee. Regardless of the motivation, it is the right thing to do. To help your workplace do the right thing, visit www.havethattalk.ca to get started.

\section{REFERENCES}

Cancelliere, C., Cassidy, J. D., Ammendolia, C., \& Cote, P. (2011). Are workplace health promotion programs effective at improving presenteeism in workers? A systematic review and best evidence synthesis. BMC Public Health, 11, 395. Retrieved from http://www.biomedcentral.com/1471-2458/11/395

Dewa, C. S., Chau, N., \& Dermer, S., (2010). Examining the comparative incidence and costs of physical and mental health-related disabilities in an employed population. Journal of Occupational and Environmental Medicine 52:, 758-62. Retrieved from http://www40.statcan.ca/101/cst01/labor21a-eng.htm

Guarding Minds at Work. (2018). Assess, protect and promote psychological health and safety. Retrieved from https:// www.guardingmindsatwork.ca/

Lamontagne, A. D., Martin, A., Page, K. M., Reavley, N. J., Noblet, A. J., Milner, A. J., Keegel, T., \& Smith, P. M., (2014). Workplace mental health: Developing an integrated intervention approach. BMC Psychiatry, 14, 131. Retrieved from: https://bmcpsychiatry.biomedcentral.com/articles/10.1186/1471-244X-14-131

Mental Health Commission of Canada. (2016). The Mental Health Commission of Canada's 2017-2022 Strategic Plan. Retrieved from https://www.mentalhealthcommission.ca/sites/default/files/2016-06/mhcc strategic plan_2017_2022_eng.pdf 